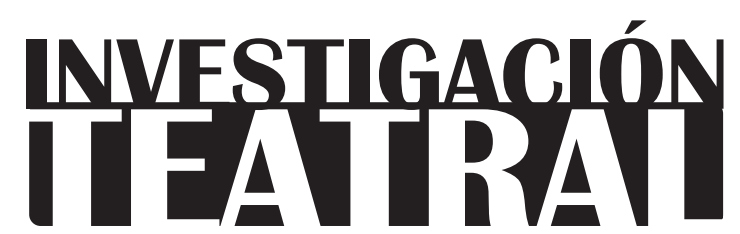

Revista de artes escénicas y performatividad

Vol. 10, Núm. 16

octubre 2019-marzo 2020

Segunda época

ISSN impreso: 1665-8728

ISSN electrónico: 2594-0953

Universidad Veracruzana

Reseña de la puesta en escena:

\title{
Stereopresence, de Cristina Maldonado
}

\author{
Teodora Elvira Lara Lecuona*
}

* Maestría en Artes Escénicas, Universidad Veracruzana,
México.
e-mail: leviravisual@gmail.com

Recibido: 12 de abril de 2019

Aceptado: 27 de agosto de 2019

Doi: $10.25009 /$ it.v10i16.2610 


\section{Stereopresence, de Cristina Maldonado}

tereopresence es un videoperformance en el que la artista mexicana Cristina Maldonado (1979) explora escénicamente la imagen y materialidad del cuerpo mediante dispositivos de proyección de video en vivo y circuito cerrado. Describe su obra como un "videoperformance escénico", en el que su cuerpo interactúa en la escena con los dispositivos de proyección de video y circuito cerrado para generar metáforas sobre las ideas de tiempo, muerte, memoria y realidad.

Maldonado desarrolla su trabajo entre las ciudades de Praga (República Checa) y Querétaro (México). Su trayectoria artística incluye la realización de proyectos artísticos en los cuales explora la interacción entre el cuerpo y la tecnología. Además del videoperformance, trabaja medios como instalación, danza de contacto y coreografía de usos múltiples. Stereopresence tuvo una gira por México durante agosto de 2018 y se presentó en tres ciudades: México, Querétaro y Guadalajara. La presente reseña se basa en la presentación a la que asistí el 17 de agosto en el Teatro de Cámara de la Facultad de Bellas Artes de la Universidad Autónoma de Querétaro y dos entrevistas posteriores que realicé a la artista.

La producción de Stereopresence estuvo a cargo Maria Cavina, directora de jedefrau.org, casa productora que obtuvo el presupuesto del Ministerio de Cultura Checa para realizar el montaje y la gira por México. El proceso creativo tuvo una duración de cuatro años y estuvo dividido en tres fases. En la primera - tres años iniciales-, la artista se dedicó a la exploración del cuerpo en interacción con las cámaras, las proyecciones de video y el circuito cerrado. En la segunda -durante el cuarto año-, tras haber obtenido el recurso del Ministerio de Cultura Checa, trabajó la dramaturgia en colaboración con Sodja Zupanc Lotker. En la tercera -últimos seis meses-, se integró el equipo de sonido, iluminación y 
INVESTIGACIÓNTEATRAL

Revista de artes escénicas y performatividad

Vol. 10, Núm. 16

octubre 2019-marzo 2020
Stereopresence, de Cristina Maldonado

Teodora Elvira Lara Lecuona

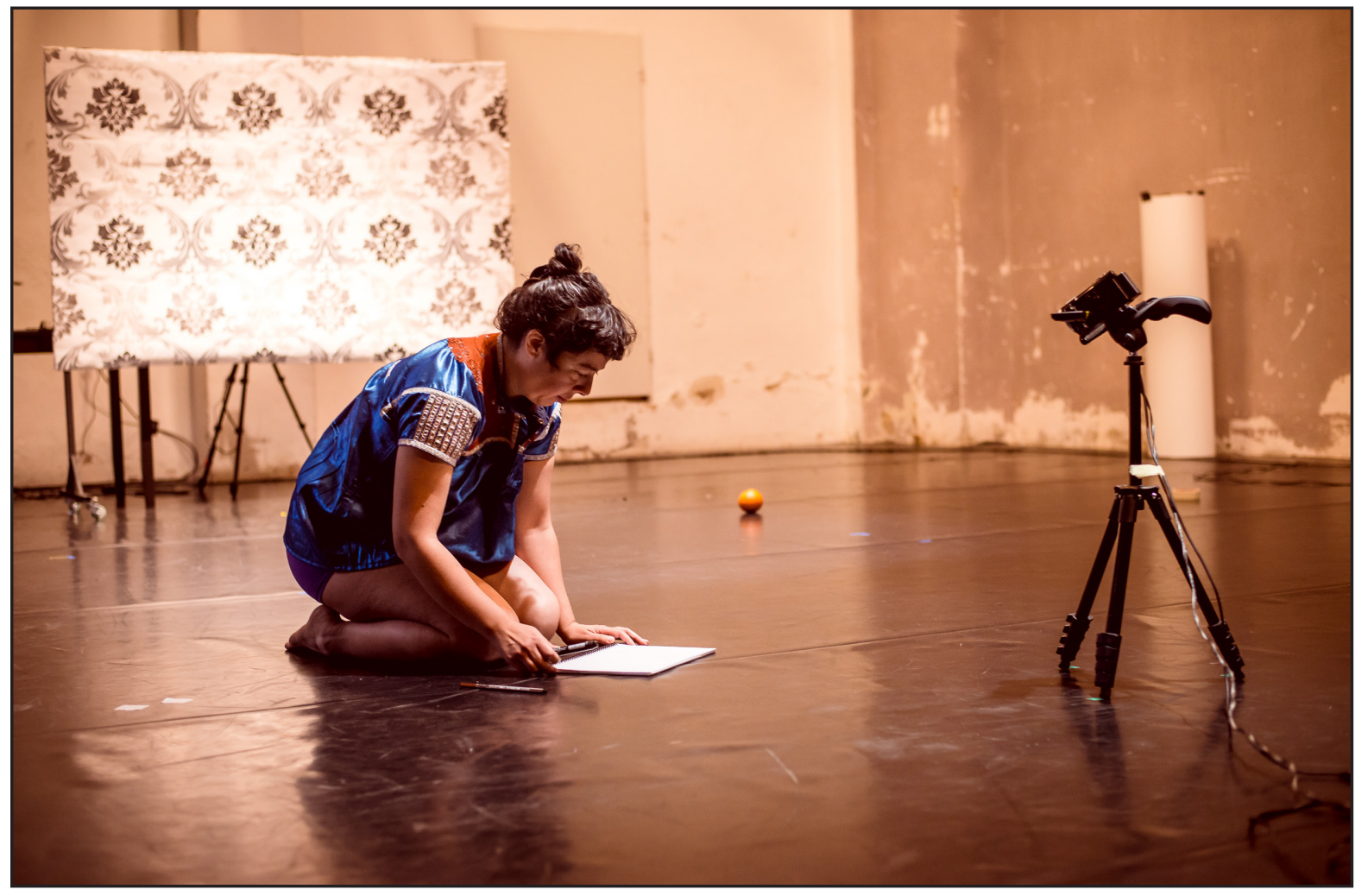

Stereopresence, Cristina Maldonado escribiendo en un papel mientras es grabada por una cámara. Teatro Estudio Alta, Praga, 2016. Fotografía de Zbynek Riedl, cortesía de Cristina Maldonado.

actuación. Durante su gira por México, Ana María Errasti y Lamija Čehajić fueron las otras dos performers en escena; Israel López, el encargado del diseño sonoro, y Šimon Janíček, de la iluminación.

\section{La estética de la desaparición}

Por lo general, las artes escénicas, incluido el performance, se entienden como acontecimientos únicos e irrepetibles, que mueren mientras tienen lugar y que, por lo tanto, van desapareciendo ante nuestros ojos. En cambio, el video se piensa como un soporte material que se conserva para convertirse en archivo.

Artistas como Cristina Maldonado dialogan con dispositivos de video de tal forma que estas nociones resultan limitadas. Además de utilizar videos de archivo que proyecta en 
vivo, Maldonado utiliza un sistema de circuito cerrado. En Stereopresence, las acciones proyectadas no son grabadas en un dispositivo, sino que se transmiten dentro del espacio escénico y desaparecen junto con la acción sin registro archivable.

En su performance, el video funciona como una imagen efímera, es decir, que desaparece en el tiempo conforme es proyectada. Si bien no escapa de ser copia de la acción que presenta simultáneamente en vivo, desafía su cualidad de permanencia. El video transmitido y proyectado en vivo aparece y desaparece como la misma existencia de los movimientos corporales. Este video no es archivo porque no permanece y, para permanecer, necesita, al igual que el performance, que se le documente.

\section{La interacción escénica entre cuerpo y dispositivos de video}

Stereopresence es una pieza que se caracteriza por la interacción en vivo de la artista con las imágenes proyectadas. Las imágenes se presentan gracias al uso de aparatos tecnológicos que permiten la proyección de video digital. Las proyecciones son de dos tipos: el circuito cerrado, que corresponde a la transmisión de acciones que están pasando en la escena, gracias a cámaras conectadas directamente a proyectores, y el video en vivo, que son proyecciones de imágenes pregrabadas que se reproducen desde una computadora y se proyectan durante una acción pública.

En Stereopresence, Maldonado graba y proyecta videos que generan la ilusión de múltiples realidades simultáneas. Logra esto mediante los siguientes artefactos: dos estructuras rectangulares sobre ruedas que sirven de soporte a pantallas de papel blanco, cuatro proyectores montados sobre bases de madera con ruedas, cuatro cámaras (una go pro y tres handycams), dos computadoras portátiles y dos teléfonos celulares. Una de las cualidades de este performance es justamente la interacción entre el cuerpo de la artista y dichos objetos en el espacio escénico. Con ello, genera imágenes híbridas que presentan niveles simultáneos de realidad.

Lo más complicado del proceso, según me señaló la artista en entrevista (2019), "fue realizar la composición coreográfica. Esta debía ser muy precisa, pues había que coordinar los movimientos de tres personas en escena, así como el movimiento de cables, dos computadoras, dos pantallas que se mueven ante el público, cuatro proyectores y cuatro cámaras". Resolver las dificultades que presenta una puesta en escena con estas características requiere un interés en el estudio, tanto técnico como estético, de dichos elementos.

El título Stereopresence hace referencia a la presencia en dos canales, es decir, la presencia y la representación de la presencia. Para la artista, esta pieza es un estudio de presencias simultáneas, un juego coreográfico entre el pasado y el presente, un diálogo 


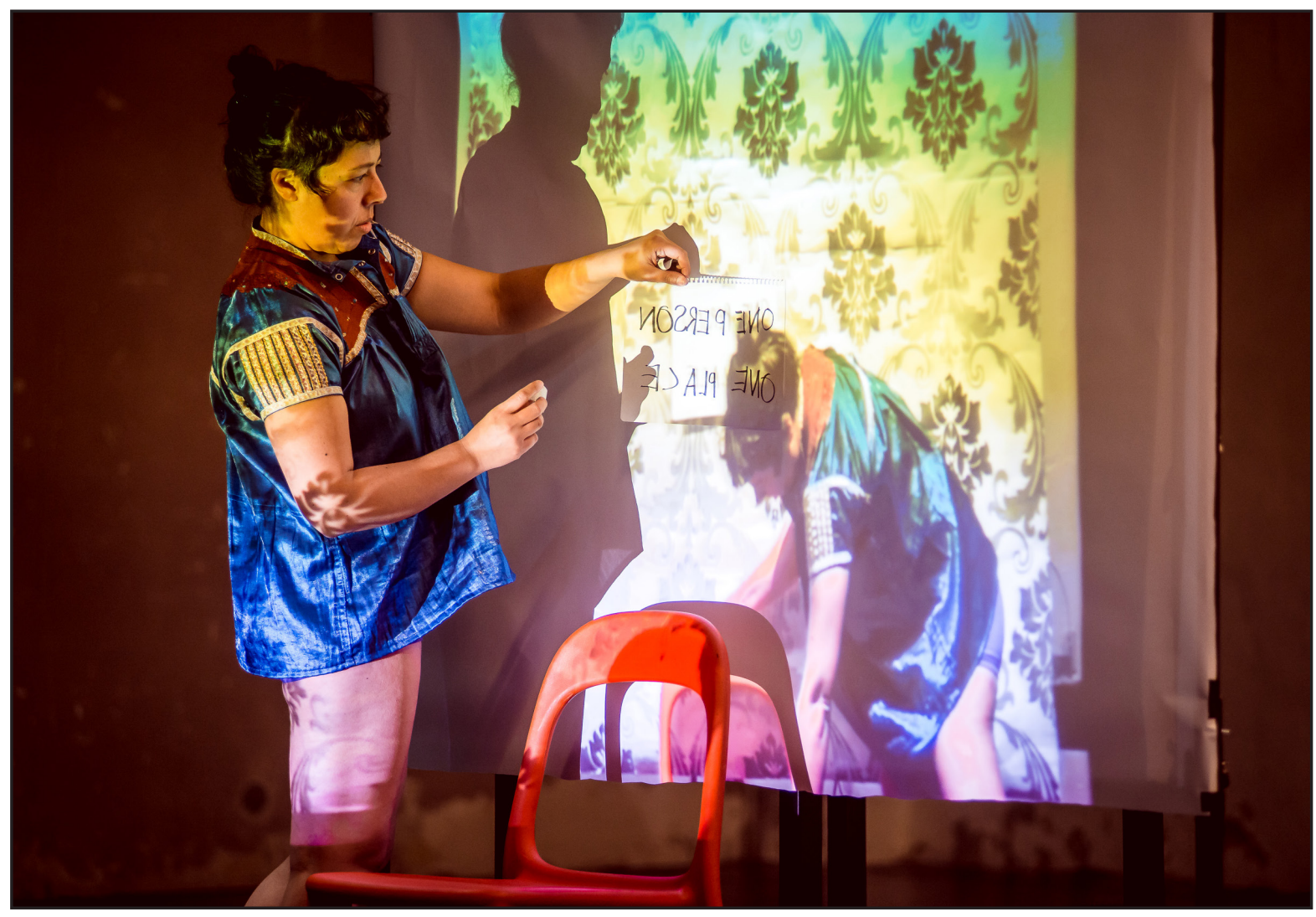

Stereopresence, Cristina Maldonado interactuando con la proyección de un video grabado unos minutos antes en el mismo espacio. Teatro Estudio Alta, Praga, 2016. Fotografía de Zbynek Riedl, cortesía de Cristina Maldonado.

personal. Este diálogo genera, en algunos momentos, una "tercera manera de estar presente". Con esto, la artista se refiere a que la yuxtaposición de las imágenes, la virtual y la real, genera una tercera presencia. Un cuerpo que es simultáneamente real y virtual. Un ejemplo es cuando la artista se encuentra semioculta detrás de la pantalla blanca, de modo que sólo la vemos de pies a rodillas, mientras que en la pantalla vemos proyectado el resto de su cuerpo, de rodillas a cabeza. Así, el área del cuerpo que la pantalla bloquea se muestra en la proyección de imágenes transmitidas en circuito cerrado.

La imagen proyectada en vivo está intencionalmente desfasada, llega con retraso; se muestran detalles del cuerpo de Maldonado que de otra forma no se podrían apreciar, a la vez que los efectos de color y distorsiones del video interrumpen la ilusión de ver al cuerpo "tal cual es". Nuestra mirada voyerista es desafiada. 


\section{El archivo personal en escena}

Stereopresence tiene una fuerte relación con la vida personal de la artista. Si bien su interés declarado es "generar distancia de lo personal para hacer una obra más universal" (2019), la pieza muestra material personal y momentos con referencias biográficas muy claras. En entrevista, la artista me explicó que el performance no es un mapa preciso de su historia y hay escenas conceptuales que no se originan de su biografía, sino de su interés en la reflexión sobre la muerte y la descomposición. A su vez, afirma que es una obra muy personal en la que hace un homenaje póstumo a su padre, quien en sus últimos años padeció Alzheimer. La pérdida de memoria es evocada en el manejo tecnológico de Stereopresence, en donde el video no retiene las imágenes, sino que éstas pasan sobre sí mismas, borrándose unas a otras sin anclarse a la materialidad de un disco duro o tarjeta de memoria.

Maldonado recupera o restaura elementos de su biografía cuando, sentada frente a una mesa, se encuentra visualmente inmersa en un video que reproduce en una computadora portátil. En este video aparece el devenir de las olas en un mar de tonalidad fría y profunda. A su lado, se encuentran otras dos mujeres que representan a su hermana y su sobrina, Ana María Errasti y Lamija Čehajić. Maldonado toma el lugar de su padre en un momento pasado y la vemos perdida en sus pensamientos. Podría decirse que esta escena es la restauración de un recuerdo. Representa, para la artista, el acompañamiento físico a una persona que está presente físicamente, pero con la mente inmersa en un mundo que no puede compartir. Una imagen de la no memoria, inasequible a su mirada o entendimiento.

Un recurso adicional del archivo personal de Maldonado es utilizar fotografías de carácter personal. Algunas de su padre y su primer viaje fuera de México. En la escena generan en ella un estado emocional de inmersión en este pasado. Para el público, aportan información que le permite el reconocimiento del padre de la artista y algunas de sus memorias físicas que permanecen en el tiempo más allá de la memoria orgánica.

Adicionalmente a las fotografías y la proyección de video en circuito cerrado, la artista proyecta videos de su archivo personal más reciente. No los grabó específicamente para la obra, sino que son parte de su documentación diaria. Con éstos, busca generar un diálogo entre el cuerpo y la proyección. En su mayoría son representaciones de la naturaleza con las que la artista se confronta. Imágenes videograbadas de bosques, lagos y mares son proyectadas en las pantallas de papel y paredes del escenario. Hay un momento en que el video parece expandirse por dos de las paredes del fondo, generando un ambiente de gran formato que envuelve a los cuerpos de las tres performers.

Stereopresence es una pieza que escenifica memorias fantasmales de la artista, quien realiza un juego entre el cuerpo orgánico y sus prótesis tecnológicas, una puesta en escena 
INVESTIGACIÓNTEATRAL

Revista de artes escénicas y performatividad

Vol. 10, Núm. 16

octubre 2019-marzo 2020

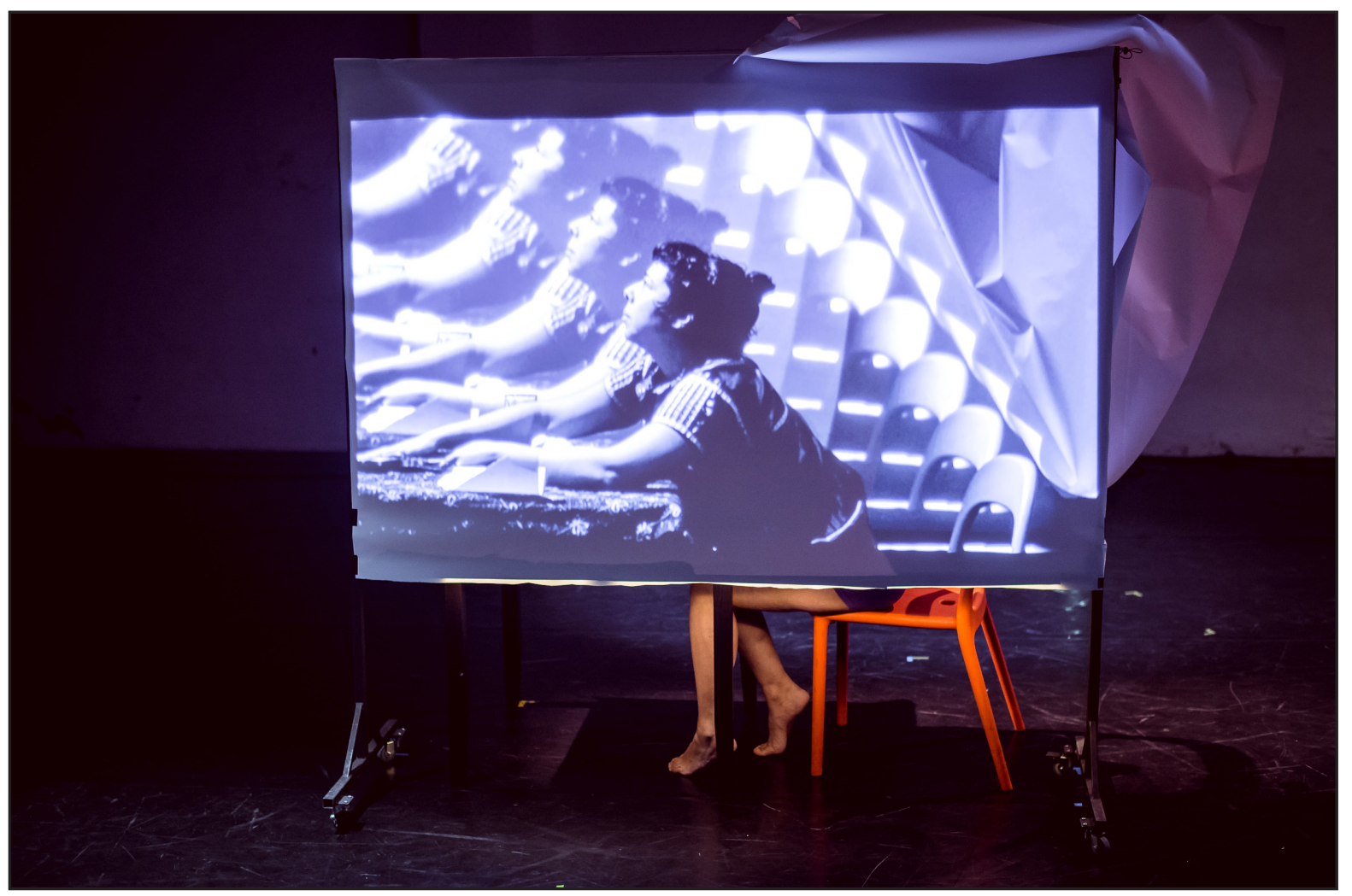

Stereopresence, acción en circuito cerrado con un efecto de feedback provocado por proyectar y grabar al mismo tiempo desde un mismo ángulo. Teatro Estudio Alta, Praga, 2016. Fotografía de Zbynek Riedl, cortesía de Cristina Maldonado.

de la memoria y el olvido, una pregunta sobre lo que permanece y lo que muere. Estamos ante una estética de la "aparición" en la que al final todo se desvanece, para re-aparecer, de manera irremediablemente parcial, en escritos como éste.

\section{Ficha técnica}

Concepto, video e instalación: Cristina Maldonado.

Performers: Cristina Maldonado, Ana María Errasti, Lamija Čehajić.

Dramaturgia: Sodja Zupanc Lotker.

Asistencia de dramaturgia: Petra Hauerová.

Diseño de iluminación: Šimon Janíček y Vladimír Burian. 
Diseño sonoro: Israel López y Tomáš Procházka.

Artefactos: Isabela Juchniewicz y Dragan Stojčevski.

Traducción: Ana Errasti.

Producción: Jedefrau.org, Stereopresence z.s.

Asistente de producción: Isabela Juchniewicz y Roberto Montiel.

Coproducción: Ministerio de Cultura Checo, Ciudad de Praga, moтus producción del teatro Alfred ve Dvoře.

Agradecimientos: Isabel Vizcaíno, Selma Lindren, Bria de la Mare, Sara Milner, Jenni Kokkomäki, Ioana Mona Popovici.

Fotografía: Zbynek Riedl.

Estreno: 25 de abril de 2017.

\section{Fuentes consultadas}

Maldonado, Cristina. Entrevista personal. 8 de febrero de 2019.

Maldonado, Cristina. Entrevista personal. 18 de agosto de 2018.

Stereopresence. Concepto, video e instalación de Cristina Maldonado, dramaturgia de Sodja Zupanc, temporada agosto de 2018, Teatro de Cámara de la Facultad de Bellas Artes de la Universidad Autónoma de Querétaro, Querétaro. 